\title{
Analisis Isi Konten Pornografi di Instagram
}

\author{
Mediatrix Rahabav, Moehammad Gafar Yoedtadi \\ mediatrix.915150143@,stu.untar.ac.id, gafary@,fikom.untar.ac.id
}

Fakultas Ilmu Komunikasi Universitas Tarumanagara

\begin{abstract}
The development of technology that has brought big changes in human life, one of which is the presence of new media that makes it easier for humans to carry out communication activities. New media has a positive impact if it wisely chooses information, news and impressions as needed. Instagram social media includes new media, which is a platform for sharing photos, videos as well as a means of building relationships between people. However, the lack of control and strict sanctions by Instagram and the government have made some users free to upload pornographic content. The@pompa.kaka account includes Instagram users who are suspected of containing a lot of pornographic content. This study aims to determine and measure how much content contains pornographic elements on the Instagram account @pompa.kaka.This study uses a quantitative approach with content analysis methods. Analysis by coding on 340 samples by coder 1 and coder 2. Coding is carried out based on 7 categories of pornography according to Law No.44 of 2008. After the coding process between coders is complete, then a reliability test is carried out to prove the validity of the data and measuring instruments. reliable. The results of this study indicate that 97\% of the content uploaded to the@pompa.kaka account contains pornographic elements.
\end{abstract}

Keywords: instagram, pornography, @pompa.kaka

\begin{abstract}
Abstrak
Perkembangan teknologi yang membawa perubahan besar dalam kehidupan manusia, salah satunya adalah kehadiran media baru yang memudahkan manusia dalam melakukan aktivitas komunikasi. Media baru membawa dampak positif apabila digunakan secara bijak dengan memilih informasi, berita serta tayangan sesuai kebutuhan. Media sosial instagram termasuk media baru, yang menjadi platform untuk berbagi foto, video sekaligus sarana membangun hubungan antar manusia. Namun kurangnya kontrol serta sanksi tegas oleh pihak instagram dan juga pemerintah membuat beberapa pengguna bebas mengunggah konten pornografi. Akun@pompa.kaka termasuk pengguna Instagram yang diduga banyak memuat konten mengandung unsur pornografi. Penelitian ini bertujuan untuk mengetahui serta mengukur berapa banyak konten yang mengandung unsur pornografi pada akun instagram @pompa.kaka. Penelitian ini menggunakan pendekatan kuantitatif dengan metode analisis isi. Analisa dengan melakukan coding pada 340 sampel oleh coder 1 dan coder 2. Coding dilakukan berdasarkan pada tujuh kategori pornografi sesuai Undang-undang No.44 tahun 2008. Setelah proses coding antar coder selesai, kemudian dilakukan uji reliabilitas untuk membuktikan keabsahan data serta alat ukur yang reliabel. Hasil penelitian ini menunjukan bahwa 97\% konten yang diunggah pada akun @pompa.kaka mengandung unsur pornografi.
\end{abstract}

Kata Kunci: instagram, pornografi,@pompa.kaka

\section{Pendahuluan}

Teknologi informasi terus berkembang dan memberikan kemudahan bagi pengguna untuk mengakses berbagai perangkat komunikasi. Salah satunya adalah 
media sosial yang memberikan kemudahan pengguna untuk berinteraksi kapan saja dan dimana saja tanpa memikirkan jarak. Hal tersebut membuat teknologi informasi dijadikan kebutuhan primer yang selalu ada di kegiatan sehari-hari. (Fitri, 2017:119)

Internet merupakan teknologi yang banyak digunakan sebagai media komunikasi sosial oleh hampir seluruh negara, termasuk di Indonesia (Alyusi, 2017: 2). Pengguna internet di Indonesia mengalami pertumbuhan. Menurut data hasil survei Hotsuite We Are Social (2020), jumlah pengguna internet di Indonesia mencapai 175,4 juta orang atau $64 \%$ dari total penduduk Indonesia sebanyak 272,1 juta orang.

Media sosial adalah aplikasi yang lahir dari teknologi internet Web 2.0. Hal itu memungkinkan sebuah penciptaan dan pertukaran data antar pengguna usergenerated content (Kinanti dan Putri, 2017:55). Media sosial tidak hanya digunakan oleh perorangan tetapi juga kelompok dan organisasi dalam memproduksi serta membagikan konten informasi secara langsung melalui telepon pintar, komputer dan laptop yang terhubung dengan internet lewat beragam fitur yang mampu menarik lebih banyak perhatian pengguna dan kemudian menjadi salah satu bagian penting dalam masyarakat.

Instagram merupakan aplikasi yang dirancang Kevin Systrom dan Mike Krieger pada tanggal 6 oktober 2010 sebagai aplikasi memungkinkan pengguna mengambil dan berbagi foto dengan beragam filter yang tersedia dan membagikan kepada sesama pengguna instagram maupun berbagai media sosial lainnya. Instagram, dapat membentuk citra diri pengguna sehingga dapat menarik banyak respon seperti peningkatan jumlah pengikut, like, dan komentar (Zakirah, 2017:5). Berdasarkan hasil survey dari WeAreSocial.net dan Hootsuite, instagram berada di urutan ke tujuh dunia dalam jumlah pengguna dan menjadi salah satu media sosial paling populer yang digunakan masyarakat.

Pornografi berdasarkan UU No. 44 Tahun 2008 adalah gambar, sketsa, ilustrasi, foto, tulisan, suara, bunyi, gambar bergerak, animasi, kartun, kecakapan, gambar tubuh, atau bentuk pesan lainnya melalui berbagai bentuk media komunikasi dan atau pertunjukan dimuka umum, yang memuat kecabulan atau eksploitasi seksual yang melanggar norma kesusilaan dalam masyarakat. Sedangkan Pornoaksi adalah penampilan yang sedikit banyak menonjolkan hal-hal seksual, misalnya gerakan-gerakan yang merangsang atau cara berpakaian minim yang menyingkap sedikit atau banyak bagian-bagian yang terkait dengan alat kelamin. Adapun menurut Kamus Besar Bahasa Indonesia (KBBI) pornografi adalah penggambaran tingkah laku secara erotis dengan lukisan atau tulisan untuk yang sengaja dibuat untuk membangkitkan nafsu birahi dalam seks.

Realita fenomena pornografi di media sosial menjadi hal yang tidak dapat dipungkiri karena perkembangan pornografi semakin luas dengan kehadiran internet yang menjadi sarana terjangkau dan mudah diakses tanpa biaya yang mahal, seolaholah tidak memiliki batas ruang untuk pengguna menyebarkan pornografi (Himawan, 2018:81).

Akun@pompa.kaka adalah salah satu username akun instagram bersifat publik dengan memiliki pengikut sebanyak 1.837 orang dan memuat konten video goyangan yang dilakukan oleh perempuan dan dengan bebas dapat diakses oleh siapapun, kalangan manapun tanpa batas usia. Instagram seharusnya dapat digunakan untuk berbagi, mengedukasi serta memberikan pengaruh positif, tetapi oleh oknum tertentu malah digunakan untuk mengunggah hal negatif hanya untuk kepentingan 
pribadi, dan kelompok tertentu demi mendapatkan keuntungan. Fenomena ini tentu tidak akan terjadi apabila pemerintah bersikap tegas berdasarkan aturan dan undangundang pornografi yang dibuat. Namun sayangnya, semua itu tidak dijalankan dengan baik dan media sosial sudah menjadi sarana pengguna untuk berbagi konten pornografi. (Anwar, Iriani, dan Manongga, 2018:2) Berawal dari masalah tersebut maka peneliti memilih akun@pompa.kaka untuk diteliti mulai dari periode 08 November 2019 hingga 19 Oktober 2020.

Penelitian ini menggunakan teori New Media, untuk menjelaskan segala sesuatu ang berkaitan dalam menyalurkan informasi dari pemberi kepada penerima informasi serta memudahkan seseorang untuk menemukan hal yang diinginkan seperti hiburan, informasi, sarana pendidikan maupun sebagai media transaksi jual beli (Efendy, Astuti dan Rahayu 2017:2).

Berdasarkan latar belakang diatas maka rumusan masalah penelitian ini yaitu berapa banyak konten yang mengandung unsur pornografi pada akun@pompa.kaka? dan berapa banyak bentuk pornografi dan pornoaksi yang ada di akun @pompa.kaka? Tujuan dari penelitian ini adalah untuk melakukan analisa isi unsur pornografi pada akun Instagram @pompa.kaka.

\section{Metode Penelitian}

Penelitian ini menggunakan pendekatan kuantitatif dengan metode analisis isi deskriptif, yaitu penelitian untuk mengetahui variabel mandiri, satu atau lebih dan tanpa membuat perbandingan atau menghubungkan variabel-variabel tersebut (Anshori dan Iswati, 2019:12). Analisis isi adalah suatu peringkasan, kuantifikasi yang berdasarkan pada metode ilmiah yaitu objektif-intersubjektif, reliabel, valid, dapat ditiru, digeneralisasi dan pengujian hipotesis (Christi dan Farid, 2020:16). Data primer yang didapat di-coding berdasarkan kategori-ketegori yang telah dibuat oleh penulis unit yang sudah di-coding tersebut disimpan untuk menjadi bahan lampiran melalui tangkapan layar pada telepon genggam.

Berikut adalah kategori-kategori yang digunakan dalam penelitian ini berdasarkan pada Undang-undang No.44 Tahun 2008 adalah sebagai berikut:

1. Cara Berpakaian

2. Tidak Berbusana atau Terkesan Telanjang

3. Sengaja Membangkitkan Nafsu Birahi

4. Bertujuan Merangsang Birahi Orang Lain

5. Tidak Mengandung Nilai (Estetika, Ilmiah, Pendidikan)

6. Tidak Pantas Menurut Tata Krama dan Norma Etis Setempat

7. Bersifat Mengeksploitasi untuk Kepentingan Ekonomi, Pribadi dan Kelompok

Data coding berasal dari akun instagram @pompa.kaka periode 8 November 2019 - 19 Oktober 2020. Jumlah sampel 345 unit diakses langsung oleh peneliti lewat izin dari pemilik akun dan kemudian akan di coding oleh coder 1 yaitu peneliti dan coder 2 Trivanno Jan, dengan jumlah unit yang sama. Kemudian hasil coding dari coder 1 dan coder 2 akan diuji apakah hasil tersebut reliabel atau tidak menggunakan formula Holsti, dengan rumus:

$$
\text { Reliabilitas Antar-Coder }=\frac{2 \mathrm{M}}{\mathrm{N} 1+\mathrm{N} 2}
$$


Di mana $\mathrm{M}$ merupakan jumlah coding yang sama oleh masing-masing coder, $\mathrm{N} 1$ adalah jumlah coding yang dibuat oleh coder 1, N2 adalah jumlah coding yang dibuat oleh coder 2. Dimulai antara 0 sampai 1, 0 artinya tidak disetujui oleh semua coder dan 1 artinya disetujui oleh para coder. Dapat dikatakan bahwa kenaikan angka mempengaruhi tingkat reliabilitas. 0,7 atau 70\% merupakan angka minimum dan di atas $0,7 \%$ merupakan nilai yang menunjukan bahwa alat ukur tersebut memang reliabel, sebaliknya jika angka dibawah $0,7 \%$ berarti alat ukur tidak reliabel.

\section{Hasil Temuan dan Diskusi}

Setelah dilakukan coding dari semua coder, peneliti selanjutnya melakukan perbandingan hasil antar coder 1 dan coder 2 untuk menunjukan berapa besar persentase persamaan antar coder keseluruhan, menggunakan rumus formula Holsti. Adapun persentase dari masing-masing kategori sebagai berikut:

Tabel 1. Persentase Semua Coder

\begin{tabular}{|c|l|c|}
\hline No. & \multicolumn{1}{|c|}{ Kategori } & Persentase \\
\hline 1. & Cara berpakaian & $99,37 \%$ \\
\hline 2. & Tidak berbusana atau terkesan telanjang & $99,14 \%$ \\
\hline 3. & Sengaja membangkitkan nafsu birahi & $99,72 \%$ \\
\hline 4. & Bertujuan merangsang birahi orang lain & $99,45 \%$ \\
\hline 5. & Tidak mengandung nilai (estetika, ilmiah, pendidikan) & $99,72 \%$ \\
\hline 6. & $\begin{array}{l}\text { Tidak pantas menurut tata krama dan norma etis masyarakat } \\
\text { setempat }\end{array}$ & $72,36 \%$ \\
\hline 7. & $\begin{array}{l}\text { Bersifat mengeksploitasi untuk kepentingan ekonomi, } \\
\text { pribadi dan kelompok }\end{array}$ & $73,25 \%$ \\
\hline
\end{tabular}

Sumber: Dokumentasi Peneliti

Berdasarkan pada temuan yang dihasilkan setelah melakukan uji reliabilitas menggunakan data-data yang telah di coding oleh coder 1 dan coder 2, terdapat 345 unit sampel yang dicurigai mengandung unsur pornografi menurut hasil uji reliabilitas. Dari sampel tersebut, ditemukan 97\% mengandung unsur pornografi. Persentase tertinggi 99,72\% untuk kategori Sengaja membangkitkan nafsu birahi dan terendah yaitu $72,36 \%$ untuk kategori tidak pantas menurut tata krama dan norma etis masyarakat setempat. Berdasarkan pada persentase tertinggi maka dapat dikatakan bahwa hampir semua sampel didominasi oleh kategori tersebut.

Seharusnya konten semacam itu tidak diunggah secara bebas di instagram karena dapat membawa pengaruh buruk jika dilihat oleh anak dibawah umur. Konten mengandung unsur pornografi tidak sesuai dengan tata krama dan norma setempat mempunyai angka yang cukup tinggi walaupun berada di urutan terendah. Patut disayangkan, meskipun sudah jelas unsur tersebut melanggar norma masyarakat, tetapi tetap dibiarkan berada di instagram tanpa dikenai sanksi atau denda tertentu untuk memberikan efek jera kepada pengunggahnya. 
Pornografi merupakan tindakan yang dilarang dan ada aturan yang mengikat yaitu Undang-undang No.44 Tahun 2008. Dengan adanya aturan tersebut seharusnya dapat mengurangi atau bahkan meniadakan penyalahgunaan media sosial untuk penyebaran konten pornografi. Namun, kurangnya perhatian serta tindakan tegas dari pemerintah dan pengawasan dari pihak instagram, sehingga oknum-oknum tertentu kemudian mengabaikan apa aturan yang ada demi menyebarkan konten pornografi di media sosial instagram secara bebas sehingga menjadi konsumsi publik.

Seperti yang telah tercantum dalam Undang-undang No.44 Tahun 2008 tentang larangan dan pembatasan, yaitu melarang tentang pembuatan, distribusi, dan kepemilikan materi pronografi. Tetapi disayangkan bahwa tidak diawasi serta diberlakukan secara baik oleh pemerintah dan pihak instagram sehingga aturan tersebut sangat bertolak belakang dengan apa yang saat ini terjadi di media sosial instagram sesuai hasil penelitian yang didapat pada akun@pompa.kaka.

Penyebaran yang luas, cepat serta mudah terjadi di media instagram, untuk itu diperlukan perhatian serta penanganan yang baik dari pemerintah sehingga pornografi pada media sosial dapat diawasi dan tidak berkembang bebas dan menimbulkan dampak negatif bagi masyarakat. Tidak hanya diperlukan pengawasan dari pemerintah dan pihak instagram, namun diharapkan adanya kesadaran dari masing-masing pengguna instagram dalam hal ini harus bijak dalam bersosial media. Sehingga tercipta media baru yang sehat dan pengguna yang peduli tentang lingkungan sosial.

Media sosial instagram seharusnya menjadi wujud inovasi dari media baru yang dapat memberikan dampak positif bagi para pengguna. Salah satu cara yang dapat dilakukan untuk mencegah adanya konten pornografi di instagram yaitu dengan mengoptimalkan kinerja gatekeeper sebagai filter tayangan, serta tindakan apa saja yang boleh dan tidak untuk dilakukan oleh pengguna dan bekerja sama dengan pemerintah sehingga dapat memberlakukan sanksi sesuai dengan kesalahan yang dibuat pengguna. Sehingga kebebasan yang diberikan dapat diawasi dengan baik dan membawa perubahan positif bagi lingkungan sosial.

Hadirnya web 2.0 mengubah batas antara khalayak dan media. Kehadirannya membuat setiap orang kini dapat menjadi produsen konten media (pengirim pesan) lewat unggahan foto dan peristiwa yang diketahui melalui status. Terlepas dari kekurangan yang dimiliki, web 2.0 memiliki kelebihan yang dapat mendukung perkembangan media yakni sebagai berikut :

1. Khalayak memiliki kontrol: Khalayak dapat ikut berpartisipasi dalam menyebarkan informasi.

2. Mengubah praktisi kerja: Jika pada media 1.0 jurnalis harus memiliki kemampuan dalam menyajikan berita, maka kini jurnalis dituntut harus bisa berkolaborasi serta sharing dan jaringan .

3. Mengubah cara advokasi dalam gerakan sosial: Tidak perlu menunggu keputusan dari media terhadap apa yang ingin ditayangkan. Pemimpin dan pelaku sosial mempunyai kendali untuk menyampaikan gerakan sosial ke media.

Ketika membahas tentang pengaruh media 2.0 serta tindakan apa yang seharusnya dilakukan oleh media sosial instagram, maka hal penting yang tidak boleh dilupakan bahwa media hanya merupakan sarana untuk menyalurkan informasi tentang apa yang sedang terjadi dan kemudian berkembang menjadi sarana untuk membangun hubungan antar sesama manusia tanpa harus memikirkan jarak. Masyarakat atau lebih tepatnya pengguna media merupakan makhluk hidup yang 
dikaruniai akal budi dan pikiran, sehingga memiliki peran aktif dalam mengontrol diri sendiri terhadap tayangan serta informasi apa yang dibutuhkan demi memenuhi kebutuhan tertentu. Hal positif dan negatif keduanya dapat ditemukan dalam media sosial khususnya instagram, media dapat dikatakan membawa dampak positif atau negatif tergantung apa yang dicari dan ditonton oleh pengguna itu sendiri. Oleh karena penerapan sanksi serta aturan yang tepat oleh instagram dan kebijakan pengguna dalam menentukan tayangan serta konten yang akan menentukan dampak apa yang akan didapat.

\section{Simpulan}

Media sosial instagram merupakan platform untuk berbagi foto, video dan menjalin hubungan antar pengguna, namun kurangnya kesadaran serta rasa tanggung jawab dalam menggunakan instagram sehingga muncul masalah seperti yang ditemukan dalam akun@pompa.kaka yaitu ada 97\% kontennya mengandung unsur pornografi.

Hal tersebut sangat disayangkan karena instagram seharusnya dapat menjadi wadah untuk pengguna dalam mencari dan menemukan informasi berupa tayangan positif yang bermanfaat dan mengedukasi, serta menjadi wadah untuk menyalurkan bakat yang dimiliki oleh setiap pengguna. Ketika instagram memiliki kelemahan dalam pengawasan terhadap aktivitas penggunanya, maka pada saat seperti ini dibutuhkan kesadaran dari pengguna untuk bijaksana dalam menyaring serta memilih informasi dan tayangan yang boleh atau tidak boleh untuk diterima agar dapat mengurangi dampak buruk tersebut, demi kebaikan bersama.

\section{Ucapan Terima kasih}

Terimakasih kepada Tuhan Yesus dan Bunda Maria, dosen pembimbing, dan Fakultas Ilmu Komunikasi Universitas Tarumanagara yang telah menjadi wadah terbaik untuk penulis selama menempuh pendidikan.

\section{Daftar Pustaka}

Alyusi. SD. (2016). Media Sosial: Interaksi, Identitas dan Modal Sosial. Jakarta: Kencana.

Anshori. M., Iswati. S. (2009). Metodologi Penelitian Kuantitatif. Surabaya: Pusat Penerbitan dan Percetakan UNAIR (AUP).

Anwar, MT., Iriani.A., Manongga. DHF. (2018). Analisis Pola Persebaran Pornografi pada Media Sosial dengan Social Network Analysis. Jurnal Buana Informatika. 9(1): 43-52.

Christi. HEJ., Farid. (2020). Analisis Kode Etik Jurnalistik Pemberitaan Keberagaman di Media Online. Koneksi Vol. 4, No. 1, Maret 2020, Hal 14$21,16$.

Efendy A., Astuti. PI., Rahayu. NT. (2017). Analisis Pengaruh Penggunaan Media Baru Terhadap Pola Interaksi Sosial Anak di Kabupaten Sukoharjo. Jurnal Penelitian Humaniora. 18(2): 12-24.

Fitri. S. (2017). Dampak Positif dan Negatif Sosial Media Terhadap Perubahan Sosial Anak. Jurnal Kajian Penelitian Pendidikan dan Pembelajaran. 1(2): 118-123. 
Himawan. S. (2018). Representasi Pornigrafi Pada Sosial (Analisis Semiotika Pierce Pada Aplikasi Bigo Live).

Kinanti. SP., Putri. BPS. (2017). Pengaruh Media Sosial Instagram @ZZapcoid Terhadap Brand Zap Clinic. Jurnal Komunikasi. 9(1): 53-64.

Zakirah. DMA. (2017). Mahasiswa dan Istagram (Study tentang Instagram Sebagai Sarana Membentuk Citra Diri di Kalangan Mahasiswa Universitas Airlangga). Jurnal S1 Sosiologi FISIP Universitas Airlangga. 1-21. 